\title{
ERJ Open Research: FAQs
}

\author{
Anita K. Simonds ${ }^{1}$ and Elin L. Reeves ${ }^{2}$ \\ Affiliations: ${ }^{1}$ Royal Brompton and Harefield NHS Foundation Trust, London, UK. ${ }^{2}$ Publications Office,
} European Respiratory Society, Sheffield, UK.

Correspondence: Anita K. Simonds, NIHR Respiratory Biomedical Research Unit, Royal Brompton and Harefield NHS Foundation Trust, London, UK. E-mail: A.Simondsarbht.nhs.uk

Introducing ERJ Open Research: everything you need to know about the new open access journal from the ERS http://ow.ly/OnBXf

ERJ Open Research launched in May 2015. It has been an exciting and busy couple of months since the launch and we've been pleased with the response from readers and authors that we've received so far. The editorial board has already had several teleconferences and a face-to-face meeting, and we are looking forward to our first official editorial board meeting taking place at the European Respiratory Society (ERS) International Congress in Amsterdam in September 2015, where we hope to discuss new ideas for evolving our young journal.

While we have already published an introductory editorial [1], we are pleased to be given this opportunity to introduce ERJ Open Research to the readers and authors of the European Respiratory Journal (ERJ) in the form of frequently asked questions (FAQs), based on some of the feedback we have received.

\section{Why launch a new journal?}

We know that the volume of scientific literature is growing (and probably too your own reading lists!). As a result, the top respiratory journals, including the ERJ, have increased manuscript submissions and limited space to publish, which means that there is a large amount of excellent research that still requires a publishing home. The ERS is keen to make sure that it serves its members, readers, authors and community at large by providing them with multiple opportunities to publish their work. Thus, after extensive market research, ERJ Open Research was born!

While there is a perception among some authors and readers that open access journals may have lower standards, we want to assure our readers and potential authors that ERJ Open Research is built on a principle of high quality. All papers will be rigorously peer-reviewed, as with the other publications in the ERS portfolio. ERJ Open Research's editorial board has access to the same database of peer reviewers used by the $E R J$, and expects the same high scientific standards from authors.

\section{How does it fit with other ERS publications?}

ERJ Open Research fits neatly into the ERS publications portfolio, as an original research open access journal, sitting alongside the ERJ (the society's flagship journal) and the European Respiratory Review, the society's open access review journal. Together, these journals inform and shape the educational nature of Breathe and the ongoing book series, the ERS Monograph [2].

\section{What is an open access journal?}

While some people are au fait with the term "open access", we know that there is still a lot of confusion about what this actually means. Purely making papers free to read online does not meet the accepted definition of open access, which includes redistribution (and often re-use and derivative works) rights. Employers, governments and funding bodies are increasingly putting in place policies that require that

Received: June 092015 | Accepted: June 092015

Conflict of interest: E.L. Reeves is an employee of the European Respiratory Society.

Copyright OERS 2015 
articles, as outputs of research, be "open" immediately upon publication rather than just "free". This means that they can be added to institutional repositories, re-formatted for machine reading or adapted.

ERJ Open Research is a fully open access journal. Authors have a choice of what Creative Commons (CC) licence their articles are be published under: CC-BY or CC-BY-NC. These CC licences provide a framework for what an end user is able to do with the article in terms of sharing, re-using and adapting. For more detail, please refer to the CC licence explainer document on our instructions for authors: http:// openres.ersjournals.com/site/authors/ifora.xhtml

\section{What are the costs?}

In conducting the market research for ERJ Open Research, we looked at the fees charged by other publishers for open access articles, and we surveyed our community to get feedback on their past experience with open access journals and publishers. While journals need to make money to function and survive, we found that there was definitely scope to provide a low-cost model within ERS's publishing infrastructure.

In our initial year, we will waive author fees for articles published under a CC-BY-NC licence. The fees for articles published under a CC-BY licence are outlined in our instructions for authors. Following this initial year, we will introduce a low-cost fee structure for both licences. There will be discounts for authors from less economically developed countries and authors from the lowest income countries will be given a complete waiver.

\section{What kind of content does ERJ Open Research publish?}

ERJ Open Research publishes well-conducted original research, covering the whole of the respiratory field, from basic science to clinical studies. In addition to original articles, it also publishes editorials, perspectives and reviews, with a focus on clinical signposting. Articles may be submitted spontaneously, commissioned, or stem from invitations to authors to transfer their manuscript from the ERJ submission platform.

So far, we have published reviews on new drugs in the management of tuberculosis [3] and a new look at chronic obstructive pulmonary disease (COPD) interventions [4], and research on topics as diverse as respiratory symptoms in children in Nepal [5], assessment of dysfunctional breathing [6], pulmonary rehabilitation for COPD on land and in the water [7], and respiratory specialist registrars' experience (or lack of it) in teaching juniors [8]. We will provide readers with guidance on how to interpret and put into practice new trial results... and much more. This is just the start!

\section{Why should I submit to ERJ Open Research?}

ERJ Open Research is a publication initiative of ERS, and has the full backing and support of its leadership. As a growing membership society with a wide range of conferences, courses and learning material, we are fortunate to be able to draw upon a vast network of respiratory professionals worldwide. We believe that authors recognise ERS as a premium brand and a marker of outstanding impact in the field.

In addition to the high-quality peer review process that your manuscript will go through, accepted papers will be handled with care and attention to detail. Papers will be copyedited by ERS's own dedicated editors, and your figures will be redrawn and polished prior to publication.

Publishing your work open access has the advantage that your work is available immediately online, with no barriers. ERJ Open Research will be published continuously, so lagtime from acceptance to publication will be minimal.

ERJ Open Research will aim to be listed in all the major indexes/indexing services, as soon as is possible, as we recognise that this level of visibility is considered a marker of importance for authors.

ERJ Open Research staff also work alongside authors to help them to promote their papers. ERS has a dedicated communications team, who can work with authors' institutions to coordinate press activity for key articles. The society also has an active social media presence, and is partnering with Kudos, an external company that helps authors to publicise their work, and track the outcome of their efforts.

\section{Why should I read ERJ Open Research?}

We want ERJ Open Research to become a top-priority destination for readers. Articles are published open access so no subscription is required to read them. We will only publish high-quality material so you can be sure that the research you are reading is reliable and up-to-date. As a continuous publication journal that can respond quickly to emerging topics, such as epidemics or new treatments, you can be sure that you are reading the most pertinent work in your field. 
We hope that the articles published so far give you an indication of our commitment to seeking out and publishing excellent contributions to the field.

Why not have a look and judge for yourself at http://openres.ersjournals.com/

\section{References}

1 Simonds AK. Welcome with Open arms! ERJ Open Res 2015; 1: 00013-2015.

2 Dinh-Xuan AT, Brusasco V, Wedzicha JA, et al. ERS publications: the flagship and the fleet. Eur Respir J 2012; 40 : 535-537.

3 D'Ambrosio L, Centis R, Sotgiu G, et al. New anti-tuberculosis drugs and regimens: 2015 update. ERJ Open Res 2015; 1: 00010-2015.

4 Vestbo J, Lange P. Prevention of COPD exacerbations: medications and other controversies. ERJ Open Res 2015; 1: 00011-2015.

5 Devakumar D, Ayres JG, Bartington S, et al. Cross-sectional study of asthma and rhinitis symptoms in the context of exposure to air pollution in Nepal. ERJ Open Res 2015; 1: 00004-2015.

6 van Dixhoorn J, Folgering H. The Nijmegen Questionnaire and dysfunctional breathing. ERJ Open Res 2015; 1: 00001-2015.

7 McNamara RJ, Elkins MR, Ferreira ML, et al. Smallest worthwhile effect of land-based and water-based pulmonary rehabilitation for COPD. ERJ Open Res 2015; 1: 00007-2015.

8 Kelly E, Walsh SM, Richards JB. Are respiratory specialist registrars trained to teach? The Irish experience. ERJ Open Res 2015; 1: 00019-2015. 